\title{
Shunt RF MEMS Contact Switch based on PZT-on-SOI Technology
}

\author{
Tony G. Ivanov, Jeffrey S. Pulskamp, Ronald G. Polcawich and Robert M. Proie \\ US Army Research Laboratory, Adelphi, MD 29783-1197
}

\begin{abstract}
This paper presents a novel RF MEMS contact switch based on PZT-on-SOI technology. PZT transducers provide $0.7 \mathrm{mN}$ contact force at $16 \mathrm{~V}$ bias voltage. Single crystal $\mathrm{Si}$ actuators, formed from the SOI device layer, ensure $0.7 \mathrm{mN}$ restoring force. The switch has $-0.1 \mathrm{~dB}$ insertion loss, $-29.0 \mathrm{~dB}$ return loss and $-27.4 \mathrm{~dB}$ isolation at $2 \mathrm{GHz}$. Unpackaged devices were tested in a single-cycle-resolution reliability test system and demonstrated lifetime of 100 million cycles.

Index Terms - Microelectromechanical systems
\end{abstract}

\section{INTRODUCTION}

The field of contact RF MEMS switches has experienced tremendous growth in recent years. The devices offer excellent RF performance [1] and the results have been truly impressive. Radant MEMS has demonstrated switch lifetimes in the hundreds of billions of cycles [2]. Teravicta [3] and RFMD [4] reported contact switches suitable for Automatic Test Equipment (ATE) and cell phone markets, respectively. A great number of university groups, companies and research laboratories, too numerous to list here, are actively working in the field and reporting excellent results. Most of the switches, introduced on the market to date, share the common features that they are constructed from metal films and use electrostatic actuation to convert electric signals to mechanical motion.

It was demonstrated in [5], among others, that to ensure good reliability, it is critical for the RF MEMS switches to have high contact and high restoring force. Provided that high forces are our goal, the force characteristics of the MEMS devices can be tailored by appropriate choice of structural materials. In terms of actuator material, OMRON demonstrated a switch with excellent RF performance, based on single crystal $\mathrm{Si}$ beams [6]. In terms of transducer type, in prior work we have reported piezoelectric actuation with good force performance and low actuation voltages [7].

This work introduces a novel RF MEMS switch based on PZT-on-SOI technology. The actuator consists of an elastic layer, metal electrode layer and a piezoelectric lead zirconate titanate (PZT) layer. The elastic layer is constructed from the Si device layer of the SOI substrate. The superior mechanical properties of Si provide improvement in the restoring force of the device compared with metal and/or deposited dielectric actuators. The Si beams are actuated using a thin film of PZT with a $\mathrm{Zr} / \mathrm{Ti}$ ratio of $52 / 48$, producing $0.7 \mathrm{mN}$ of contact force at 16 volts. The combination of PZT and SOI, together with the low stress of single crystal Si films, results in a switch with excellent RF characteristics and demonstrated unpackaged operation exceeding 100 million cycles.

\section{DESIGN AND FABRICATION}

A SEM micrograph of the device is shown in Fig. 1. There are 4 contact points under air-bridges in the RF transmission line. The two actuators are mechanically coupled to each other. The shared mechanical link has a conducting path to ground and houses the contact dimples. When the bias is at zero volts the actuators/contacts deflect out of the plane of the CPW line and the RF signals propagate from input to output with minimum insertion loss. When the switch is biased, the actuators deflect upwards and close the contacts. This shorts the RF signal to ground and establishes a high isolation state in the RF transmission line. DC and RF grounds are shared and DC bias voltage is provided from a separate pad.

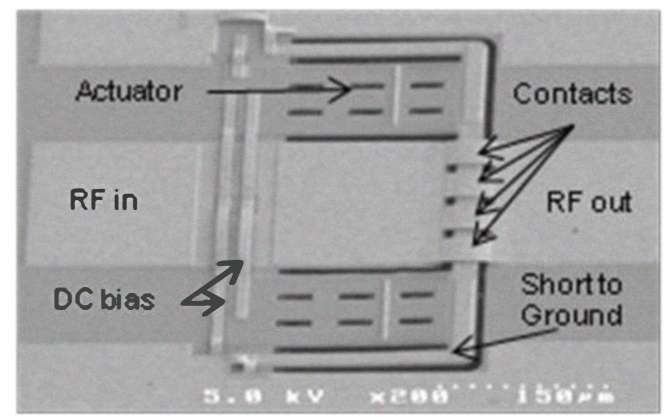

Fig. 1. SEM of shunt RF MEMS contact switch.

TABLE I

ACTUATOR THIN FILM STACK

\begin{tabular}{|c|c|c|}
\hline$\#$ & Film & $\begin{array}{c}\text { Thickness } \\
(\mu \mathrm{m})\end{array}$ \\
\hline 1 & $\mathrm{ALD} \mathrm{Al}_{3} \mathrm{O}_{5}$ & 0.005 \\
\hline 2 & Pt Top Electrode & 0.100 \\
\hline 3 & PZT (52/48) & 1.000 \\
\hline 4 & $\mathrm{TiO}_{2} /$ Pt Bottom Electrode & $0.033 / 0.100$ \\
\hline 5 & $\mathrm{SiO}_{2}$ & 0.200 \\
\hline 6 & High Resistivity Silicon & 4.000 \\
\hline 7 & $\mathrm{SiO}_{2}$ & 0.100 \\
\hline
\end{tabular}

Table I provides summary of the films forming the actuator stack. The overall mechanical performance of the stack is dominated by the properties of crystalline Si with a Young's modulus of $\sim 183 \mathrm{GPa}$. As a result, the restoring force for this actuator is $0.7 \mathrm{mN}$ and is significantly increased when compared to composite actuators using combinations of $\mathrm{SiO}_{2}$ 
( $80 \mathrm{GPa})$ and $\mathrm{Si}_{3} \mathrm{~N}_{4}$. It should be noted that the targeted PZT thickness was $1 \mu \mathrm{m}$, in order to provide $0.7 \mathrm{mN}$ contact force for sub $\mathrm{Ohm}$ contact resistance and large cycle lifetimes. The switches were designed for $1.2 \mu \mathrm{m}$ contact gap and the calculated contact and restoring forces are shown in Fig. 2.

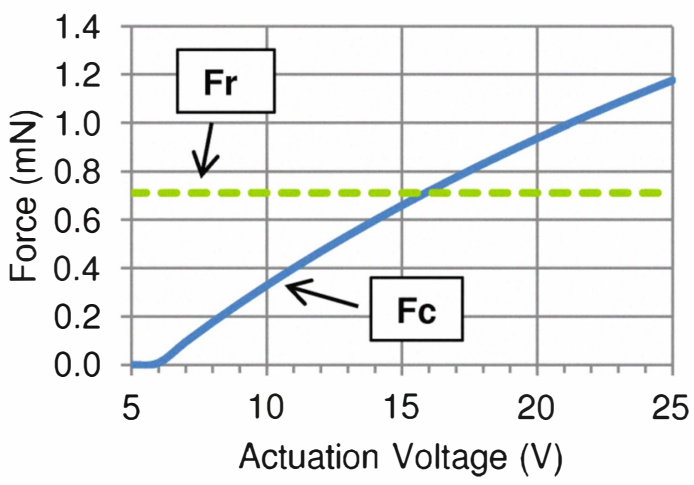

Fig. 2. Contact force $\left(F_{c}\right)$ and restoring force $\left(F_{r}\right)$ vs. voltage

The switch fabrication is done on commercially available SOI substrates. High resistivity $(>5,000 \mathrm{Ohm}-\mathrm{cm}) \mathrm{Si}$ is used for both device and handle layers. The $\mathrm{SiO}_{2} / \mathrm{TiO}_{2} / \mathrm{Pt} / \mathrm{PZT} / \mathrm{Pt}$ stack is blanket deposited and patterned, followed by patterning of the device and buried oxide layers. Thin ALD $\mathrm{Al}_{2} \mathrm{O}_{3}$ coating is applied to protect the actuator $\mathrm{Si}$ from subsequent silicon etches as well as provide hydrogen barrier protection for the PZT. The transmission lines are defined by liftoff and consist of a tri-layer of $\mathrm{Cr} / \mathrm{Pt} / \mathrm{Au}(20 / 20 / 730 \mathrm{~nm})$ coated later in the process by a layer of $2 \mu \mathrm{m}$ thick evaporated $\mathrm{Au}$ which also is used to create the air bridges for the switch contact. Contact dimples are deposited by evaporation and consist of a Au/Ru. The contact gap of approximately $1.2 \mu \mathrm{m}$ is defined by a sacrificial photoresist and the residual stress deformation of the actuators. The release process is a combination of photoresist etch using an oxygen plasma and a $\mathrm{XeF}_{2}$ etch of the handle wafer silicon.

\section{EXPERIMENTAL RESULTS}

Upon completing fabrication, the switches were initially tested for actuation. Under pulsed voltage, the switches close at $\sim 8 \mathrm{~V}$ and release at $\sim 6 \mathrm{~V}$. The actuation and response waveforms are shown in Fig. 3. Bounce free operation can be achieved with simple linear ramps of the rising and falling edges of the actuation pulse. The rise and fall times are $5 \mu \mathrm{s}$ and the high voltage portion of the pulse is $25 \mu \mathrm{s}$. Time to closure, measured from $0 \mathrm{~V}$ on the rising edge to complete closure on the response waveform, is $\sim 8 \mu \mathrm{s}$. Time to open is approximately the same. The actuators can sustain instantaneous voltage stress of more than $80 \mathrm{~V}$ and lasted more than 100 million cycles with $22 \mathrm{~V}$ actuation. More work is underway to better define the safe operation region for these devices.

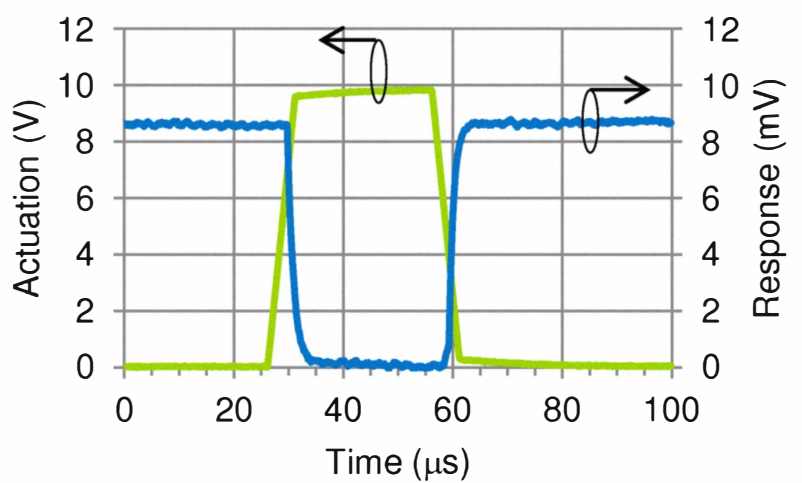

Fig. 3. Dynamic response of shunt RF MEMS contact switch

RF testing was done on wafer, with a semi automatic probe station and an Agilent E8361A network analyzer. The switch zero bias state, resulting in low insertion loss, is shown in Fig. 4. Insertion loss (IL) of less than $-0.5 \mathrm{~dB}$ is measured up to 25 $\mathrm{GHz}$, with $\mathrm{IL}=-0.1 \mathrm{~dB}$ at $2 \mathrm{GHz}$ and $\mathrm{IL}=-0.25 \mathrm{~dB}$ at $10 \mathrm{GHz}$. The corresponding return loss is $-29.0 \mathrm{~dB}$ at $2 \mathrm{GHz}$ and -22.8 $\mathrm{dB}$ at $10 \mathrm{GHz}$.

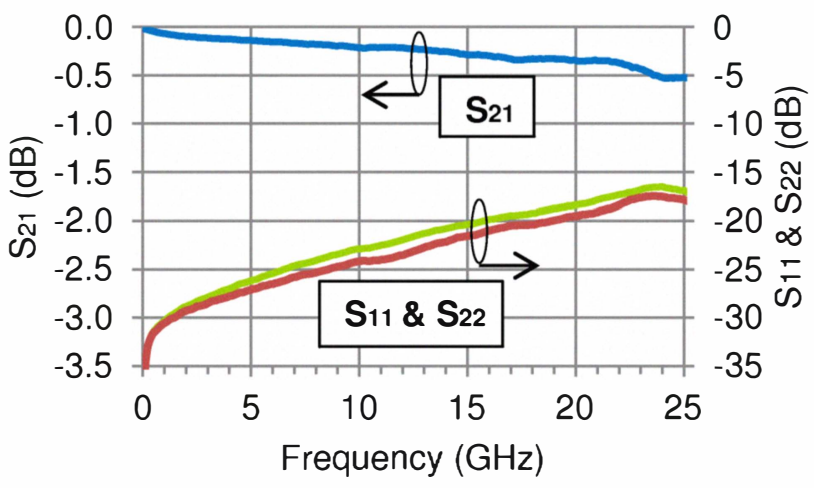

Fig. 4. RF response - low insertion loss state

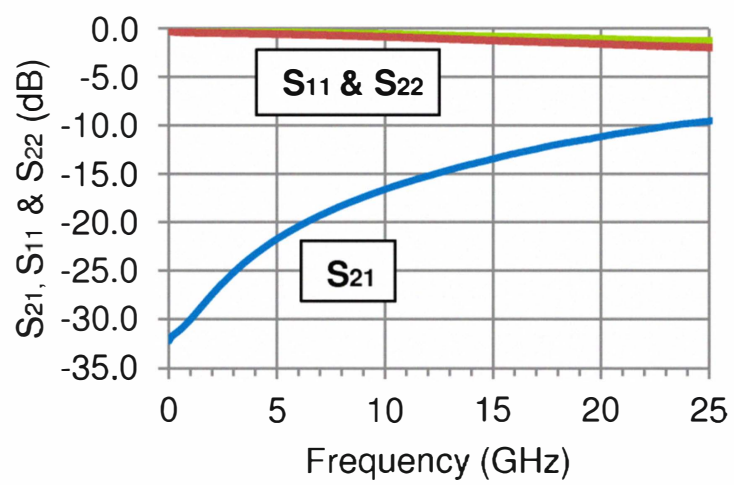

Fig. 5. RF response - high isolation state

Fig. 5 shows the switch response in the complementary state - the device is actuated and high isolation is created between the RF input and output. Measured isolation approaches -30 $\mathrm{dB}$ at low frequencies. It is $-27.4 \mathrm{~dB}$ at $2 \mathrm{GHz}$ and $-16.6 \mathrm{~dB}$ at $10 \mathrm{GHz}$. At high frequencies the isolation degrades slowly and it becomes less than $-10 \mathrm{~dB}$ at $25 \mathrm{GHz}$. The isolation at low frequencies is controlled mostly by the switch's contact 
resistance. Good isolation in that range is an indicator of low contact resistance, and respectively of high contact force. At high frequencies, the inductive reactance in the short to GND path and capacitive input to output coupling dominate.

\section{RELIABILITY}

Unpackaged switches were tested in a single-cycleresolution reliability test system, shown in Fig. 6 . The actuation pulse from Fig. 3, with value of $16 \mathrm{~V}$, was applied to the device at a $10 \mathrm{kHz}$ rate. Every cycle was binned as "pass" or "fail", in real time, and all failures were recorded. Most of the passing cycles were discarded. Periodic sampling of pass cycles was recorded, in order to monitor slow degradation of contact resistance.

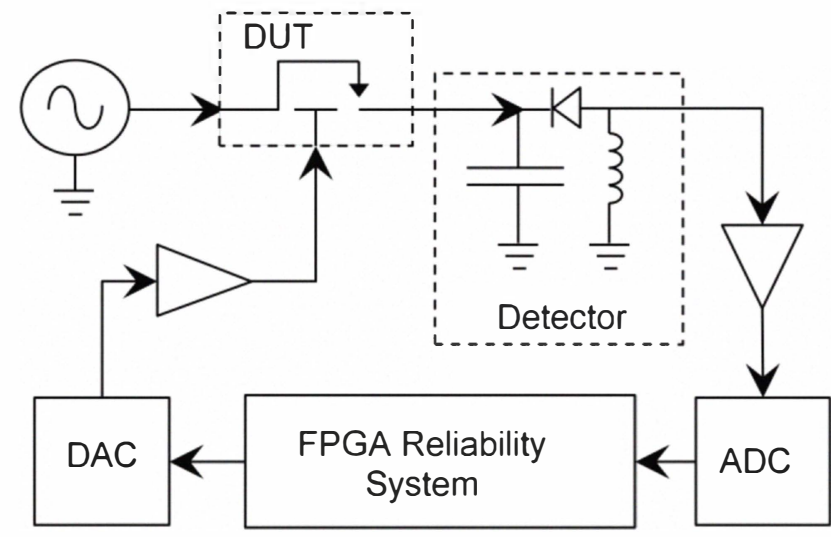

Figure 6. Reliability system block diagram.

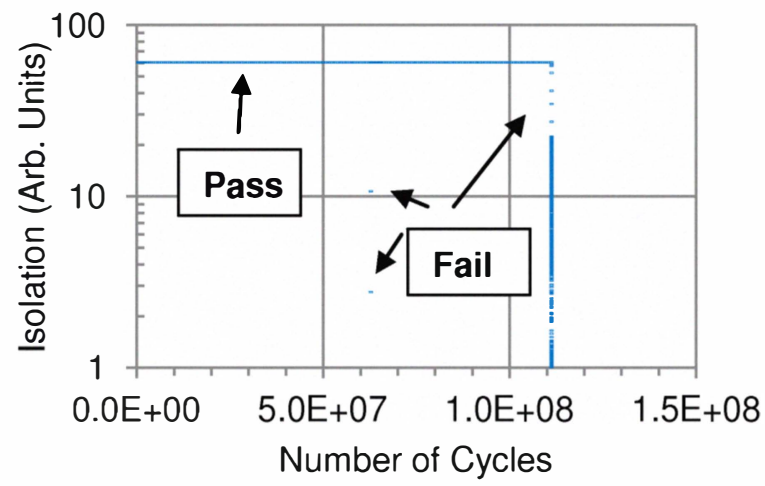

Fig. 7. Lifetime test of the shunt RF MEMS contact switch.

Fig. 7 shows the results of the lifetime test. All passing cycles are plotted at value 60 of the arbitrary isolation units. All data points less than 60 indicate failures. The RF MEMS switch operated for more than 100 million cycles. There were two intermittent failures at about 65 million cycles. Increase in the failures started after 110 million cycles, followed by catastrophic failure of the device.

A closer view of the rapid degradation region near 110 million cycles is provided in Fig. 8. The red hatched line indicates the pass/fail boundary.

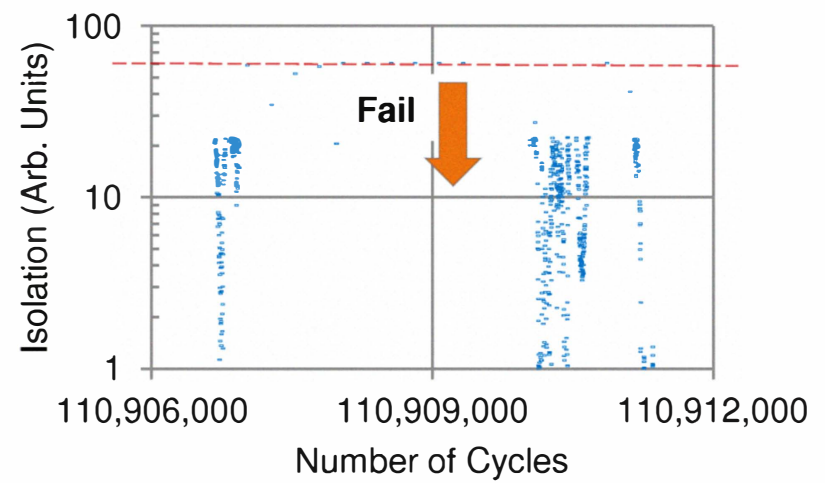

Fig. 8. Detailed view of the RF MEMS switch degradation.

Initially, the switch has a burst of failures, followed by a sequence of passing cycles. Eventually, the failures re-appear with increased frequency and the last data point indicates catastrophic failure of the device. Post failure inspection and analysis of the devices is pending.

\section{CONCLUSION}

Shunt RF MEMS contact switch based on PZT-on-SOI technology has been demonstrated. The device has insertion loss of $-0.1 \mathrm{~dB}$, return loss of $-29.0 \mathrm{~dB}$ and isolation of -27.4 $\mathrm{dB}$ at $2 \mathrm{GHz}$. Unpackaged lifetime test yielded more than 100 million cycles. The robust performance of the devices is attributed to the use of PZT transducers $\left(\mathrm{F}_{\mathrm{c}}=0.7 \mathrm{mN}\right)$, combined with crystalline $\mathrm{Si}$ actuators $\left(\mathrm{F}_{\mathrm{r}}=0.7 \mathrm{mN}\right)$.

\section{REFERENCES}

[1] G. M. Rebeiz, RF MEMS Theory, Design, and Technology. New Jersey: Wiley \& Sons, 2003.

[2] H. S. Newman, J. L. Ebel, D. Judy, and J. Maciel, "Lifetime measurements on a high-reliability RF-MEMS contact switch," IEEE Microwave Wireless Compon. Lett., vol. 18, no. 2, pp. 100102, Feb. 2008.

[3] D. A. Goins, R. D. Nelson, and 1. S. McKillop, "Design of a 20 GHz low loss ohmic contact RF MEMS switch," 2007 IEEE MTT-S Int. Microwave Symp. Dig., Honolulu, HI, June 2007, pp. 371-374.

[4] J. Costa, T. Ivanov, J. Hammond, J. Gering, E. Glass, J. Jorgenson, D. Dening, D. Kerr, J. Reed, S. Crist, T. Mercier, S. Kim, and P. Gorisse, "Integrated MEMS switch technology on SOl-CMOS," IEEE Solid State Sensors, Actuators, and Microsystems Workshop, Hilton Head, SC, June 2008, pp. 18-21.

[5] C. D. Pattel and G. M. Rebeiz, "RF MEMS metal-contact switches with $\mathrm{mN}$ contact and restoring forces and low process sensitivity," IEEE Trans. Microwave Theory \& Tech., vol. 59, no. 5, pp. 12301237, May 2011

[6] Y. Uno, K. Narise, T. Masuda, K. Inoue, Y. Adachi, K. Hosoya, T. Seki, and F. Sato, "Development of SPOT-structured RF MEMS switch," 2009 IEEE Transducers, Denver, CO, June 2009, pp. 541 544.

[7] R. Polcawich, J. Pulskamp, D. Judy, P. Ranade, S. TrolierMcKinstry, and M. Dubey, "Surface Micromachined Microelectromechancial Ohmic Series Switch Using Thin-Film Piezoelectric Actuators," IEEE Trans. Microwave Theory \& Tech, Vol. 55, pp. 2642 - 2654, Dec 2007. 